\title{
0776 THE DEVELOPMENT AND IMPLEMENTATION OF MANDATORY MOTORCYCLE HELMET LEGISLATION IN VIETNAM
}

J Passmore*, N Phuong Nam, N Lan Huong, N Trong Ha Correspondence: WHO, 63 Tran Hung Dao Hanoi, 1000, Vietnam

\subsection{6/ip.2010.029215.776}

Road traffic injuries are a leading cause of death and disability in Vietnam with 11243 deaths and 7771 serious injuries on the roads in 2008 , of which an estimated $60 \%$ of deaths occurred in motorcycle riders and passengers.

Motorcycles represent 95\% of Vietnam's 27 million registered vehicles. In recognition of this problem, Vietnam has had partial motorcycle helmet legislation since 1995, however for a variety of reasons, implementation and enforcement have been limited.

On 29 June 2007, Vietnam introduced the first universal mandatory helmet law. Taking effect on 15 December 2007, this legislation covered all riders and passengers on all roads. Penalties were increased tenfold and cohorts of police were mobilised for enforcement. 


\section{IP Safety 2010 abstracts}

Despite past barriers to enforcement, prioritisation within traffic police resulted in 680000 infringements being issued for non-wearing in 2008. In selected provinces, helmet wearing increased significantly in the first 6 months of the helmet law. In Danang, for example, increasing from $27 \%$ to $99 \%$. Preliminary data from 20 hospitals indicated that the risk of head injuries and deaths decreased by $16 \%$ and $18 \%$, respectively; in the 3 months after the helmet law was introduced.

Vietnam has a long history of limited effectiveness in helmet legislation. However, through political leadership, advance public education and stringent enforcement from the day the legislation took effect, reductions in head injuries and deaths are evident.

Continual monitoring the implementation of the legislation has identified loopholes detrimental to the effectiveness of the law which have subsequently either have been or are being addressed. 